\title{
POESIA ORAL E REITERATIVIDADE: O CASO DAS NARRATIVAS ORAIS PANTANEIRAS
}

\author{
Frederico Augusto Garcia Fernandes
}

RESUMO: This article deals with a very evident issue in poetic texts of oral circulation: the reiterativity. It is based on studies about the oral narratives from Pantanal called "burial. Dealing with a group of 37 narratives from Pantanal, some invariable elements were analyzed, such as: origin, announcement, marking, probation and epilogue, which are reiterable. But, these narratives present some variation in their utterance context, that is, in their performance. Thus, the narratives reorganized themselves, changing their meanings.

PALAVRAS-CHAVE: reiteratividade, narrativas orais, Pantanal.

\section{A poesia dos enterros: elementos reiteráveis e irreiteráveis}

Para introduzir as discussões a respeito da poesia e reiteratividade, duas considerações devem ser feitas: tomo o conceito de poesia, conforme a vai definir Paul Zumthor (2005) de modo bastante generalizado, como a "expressão do ser na linguagem". Sendo assim, entendo tanto as narrativas em prosa como em verso como manifestações poéticas. Por se tratar de uma reflexão que tem como objeto as narrativas orais pantaneiras, defino, ad hoc, a narrativa como um enunciado linear, em contraposição à circularidade da voz lírica, portanto, com diferentes marcações da dinâmica temporal que representa. Constituída, estruturalmente, por várias possibilidades de combinação entre palavras, ordens sintáticas e conteúdo, ou por diferentes suportes (oral, gestual, escrito, sonoro, visual), a narrativa apresenta um significante e um significado que geralmente variam ao ser reiterada em contextos de enunciação específicos.

Por conta de apresentar uma dinâmica no tempo que a (re)significa ou a reitera e, concomitantemente, ser uma representação do tempo que enuncia, a narrativa está, conforme acentua Roland Barthes (1976, p. 19-20),

em todos os tempos, em todos os lugares, em todas as sociedades; a narrativa começa com a própria história da humanidade; não há em parte alguma povo algum sem narrativa; todas as classes, todos os grupos humanos têm suas narrativas, e freqüentemente estas narrativas são apreciadas em comum por homens de culturas diferentes e mesmo opostas: a narrativa ridiculariza a boa e a má-literatura: internacional, trans-histórica, transcultural, a narrativa está aí, como a vida.

Minha inquietação, como pesquisador da narrativa oral pantaneira, recaiu sobre aquilo que é reiterável e os diferentes contextos de enunciação que possibilitam a reiteração de um arquétipo ${ }^{1}$ narrativo. Em outras palavras: o que se repete num conjunto de histórias orais, por quê e como se repete uma narrativa?

\footnotetext{
Doutor em Letras. Professor do Departamento de Letras Vernáculas e Clássicas da UEL, Coordenador do GT de Literatura Oral e Popular da ANPOLL (biênios 2002-2004/2004-2006).

${ }^{1}$ Aproprio-me do conceito de arquétipo de Paul Zumthor (1993, p. 145), que afirma: "Arquétipo refere-se ao eixo vertical, à hierarquia dos textos; designa o conjunto de virtualidades preexistentes a toda a produção textual. Então, mesmo que uma sequiência lingüística (texto) seja escrita, memorizada previamente à performance, ela mostra ainda o arquétipo, [que] permanece virtual, numa relação com o que será performatizado".
} 
Esta inquietação virou objeto de minha tese de doutorado, na qual faço uma reflexão a respeito da voz em performance. Isto é, embasado na idéia de Albert Lord (1960, p. 13), caudatário de Milman Parry, de que "for the oral poet the moment of composition is the performance", enfoquei como as diferentes autorias eram construídas ao longo das performances. Apesar de Lord concentrar seus estudos em poemas épicos iugoslavos, no qual emprega o conceito de "fórmula" para justificar a reiteração do texto, o conceito de "composição em performance" corrobora a idéia de que o poema épico oral não prescinde de um contexto de enunciação e que tal contexto, marcado principalmente pela relação entre o "cantor" e seu público e todos os embates ideológicos que o cercam, modela o "fazer' do novo texto. Por outro lado, meu objeto diferenciava-se do de Lord em razão de se tratar de um conjunto de narrativas orais sobre os enterros ${ }^{2}$ pantaneiros e de como elas se atualizam, com discursos e sentidos diferenciados, mesmo que preservando uma estrutura mais ou menos comum e de como essas modificações estavam diretamente ligadas à performance na qual o texto é atualizado. Logo, minha preocupação não recaiu sobre as "fórmulas" (grosso modo, a reiteração de palavras ou trechos rítmicos do texto), mas sobre os diferentes contextos de atualização e de suas implicações ideológicas.

Assim, no caso das narrativas de enterro, identifiquei quatro atualizações específicas num conjunto de 32 histórias. A primeira narrativa é o protoconto, ou seja, trata-se de uma atualização do arquétipo enterro em que ela se assemelha, do ponto de vista estrutural, ao conto maravilhoso, enfocando a trajetória de um herói que vai da miséria à riqueza, vencendo provas em que deve demonstrar coragem e lealdade. Outra narrativa de enterro atualizada é a que chamei de explicativa, que se assemelha ao mito, ou seja, o enterro se torna uma explicação para a presença de fenômenos sobrenaturais em algumas regiões. A terceira narrativa é o logro, no qual o efeito principal é o do sentido moral de que "não devemos confiar em qualquer pessoa", pois essas histórias tratam de pessoas que estiveram muito próximas de um tesouro de enterro e que foram trapaceadas por algum amigo ou estranho que chegou na região. A última forma de atualização identificada não é bem uma narrativa, mas trata-se de fragmentos de passagens dela, a que denominei de descritiva, na qual o narrador comenta fatos de como se faz para quebrar o encantamento de um enterro, das regras investidas, entre outras coisas, sem encadear suas idéias dentro de um princípio de unidade, com episódios ou situações sem entrelaçamento, permanecendo mais no campo da descrição do que da ação.

Nesse caso, pensando no que é reiterável e irreiterável nas narrativas de enterro, noto que os contextos de enunciação são irreiteráveis, pois é a sua modificação que também imprimirá uma mudança no significado das narrativas de enterro, gerando o protoconto, a explicativa, o logro e a descritiva.

Essas atualizações são consideradas reiteráveis à medida que o sentido expresso pelo narrador, ou seja, o que ele quis dizer em seu ato enunciativo, é recorrente em outras histórias. Em outras palavras, uma narrativa de enterro com o sentido de logro, por exemplo, sempre apresentará um herói que teve seu plano de retirada do enterro frustrado por ter sido enganado por outra pessoa. Por outro lado, do ponto de vista textual, os elementos da trama (personagens e espaços representados, principalmente) quase sempre não são os mesmos. Isso quer dizer que o problema da reiteração não se concentra no modo como se diz, mas naquilo que é dito. De uma outra perspectiva, os narradores podem atribuir um mesmo sentido à narrativa que do ponto de vista de sua trama são diferentes.

Sob outro prisma, alguns subtemas deste tema maior chamado enterro, que denominei como partes, permanecem reiteráveis. As chamadas partes advêm de uma consciência linguiística do narrador que assimilou um determinado encaminhamento narrativo do arquétipo, mas que, ao atualizá-lo, não segue necessariamente uma ordem preestabelecida, fazendo com que as partes tornem-se amovíveis. Assim, nem todas as cinco partes que identifiquei nas narrativas de enterro (origem, anunciação, manifestação, provação e desenlace) são reiteráveis em todas as narrativas de enterro, mas é necessário, ao menos, a verbalização de uma delas para que a narrativa se configure como enterro. Por isso, elas são o elemento reiterativo das narrativas de enterro.

É claro que, quando trato a parte como um elemento reiterativo da narrativa, não estou afirmando que o seu enunciado seja, também, reiterativo. Por exemplo, se se tomar a parte provação, que diz respeito ao modo como um escolhido deve proceder para retirar o tesouro enterrado e quebrar seu encantamento, tem-se que: 1) o escolhido não pode contar nada para alguém, pois do contrário o dinheiro vira carvão; 2) o escolhido só deverá pensar no que vai fazer com o dinheiro quando ele estiver de posse dele; 3) o escolhido deve "batizar" com sangue o tesouro, pois o ouro é vivo e corre pela terra, entre outras provas possíveis. Nesse sentido, o que se reitera em todos esses enunciados é a ação pela qual se evidencia a provação de um escolhido para ficar com o enterro e não o que cerca esta ação.

\footnotetext{
${ }^{2}$ Denomino por "enterros" histórias que, de modo geral, tratam de um tesouro que foi enterrado e ficou encantado, pois, enquanto ele não for descoberto por alguém, a alma da pessoa que o enterrou fica assombrando o lugar.
} 
Essas partes aproximam-se muito daquilo que Propp (1984) denominou "motivo". A proposta morfológica proppiana contribuiu bastante para um estudo sobre a variação dentro das narrativas orais. Conseqüentemente, por meio da variação, chega-se facilmente à problemática da reiteração. No entanto, a proposta que apresento guarda uma sensível diferença em relação à de Propp, uma vez que levo em conta o contexto na análise da narrativa e a maneira como ele vai contribuir para "moldar" a variação. Foi LéviStrauss, no posfácio da edição brasileira de Morfologia do Conto Maravilhoso, quem critica Propp pela ausência do contexto na interpretação morfológica. Em suas palavras:

Cada personagem não é apresentado sob forma de um elemento opaco, diante do qual a análise estrutural deve deter-se a dizer não irás além [...] e o personagem aí [na morfologia proppiana] é comparável a uma palavra encontrada num documento, mas não dicionarizada, ou ainda, a um nome próprio, isto é, um termo desprovido de contexto (LÉVI-STRAUSS. In: PROPP, 1987, p. 197).

\section{Mythos e epos: outros aspectos da reiteratividade}

Já que proponho uma discussão a respeito da reiteratividade de um arquétipo numa narrativa oral, torna-se importante pensar aquilo que é reiterável e o que não o é. Nesse sentido, o compositor, poeta e filósofo Antonio Cicero (2005), numa reflexão a respeito do que é reiterável e irreiterável na cultura grega da Antigüidade, observa que Homero empregava a palavra mythos e epos em sentido diferenciado. Mythos era entendido como a história, um ato de fala, que ordena, interroga, exorta, solicita etc; já o epos, como a palavra, o discurso, aquilo que depende de uma aceitação social. Pois, stricto sensu, "cadeira" implica, em seu ato enunciativo, não apenas uma ordem de sons, mas no aceite entre os sujeitos comunicantes daquilo que se entende como cadeira e não outra coisa, e, portanto, torna-se reiterável à proporção que é enunciada. O mythos, assim, torna-se um enunciado não-reiterável, pois os atos de fala modificam-se conforme as circunstâncias comunicativas, ou seja, ela não possui uma existência virtual (CICERO, 2005, p. 267). Ou, conforme acentua Cicero (2005, p. 258):

O mythos dito por fulano é aquilo que ele disse, mas não as palavras com que o disse, isto é, não os ipssima verba que pronunciou, e sim aquilo que essas palavras disseram e pode ser dito também com outras palavras. Aquilo que pode ser dito com diferentes palavras é o que chamamos de conteúdo. Assim, o mythos acaba por se identificar com o conteúdo ou o significado daquilo que se diz.

Na perspectiva colocada por Cicero, o epos estaria para o significante, como o mythos para o significado. Assim, o mythos pode ser considerado "aquilo que se diz em um contexto de enunciação específico", mas não pode ser entendido como a "forma pela qual é dito", pois isto entraria no campo de discussão do epos. Assim, o epos é um discurso reiterável, que "consiste num objeto, pois a reiteratividade - em particular a reiteratividade social ou institucional - é o procedimento primordial através do qual uma ação - no caso em questão, um ato de fala - se transforma em objeto" (CICERO, 2005, p. 250).

No entanto, não se pode descartar o fato de que podemos (i) "dizer coisas diferentes com as mesmas palavras" e, ao contrário, (ii) "dizer a mesma coisa com palavras diferentes". Ou seja, a alegoria "água mole e pedra dura, tanto bate até que fura" trata-se de um epos, pois é reiterável em decorrência da repetição de uso específico de palavras e da ordem dessas palavras, mas o significado deste provérbio pode variar de acordo com os contextos de enunciação em que ele for atualizado. Assim, o epos de que trato pode dizer que "não se podem perder as esperanças" ou "que alguém é muito teimoso" ou, ainda, "que pequenos problemas crônicos podem se tornar grandes problemas", entre várias outras possibilidades. A reiteração do significante, como já entrevisto acima, não implica a reiteração do significado. Pode-se dizer, no caso da alegoria tomada como exemplo, que se trata de um epos com função de mythos, pois os contextos enunciativos são variáveis, ao passo que o texto per se é reiterável.

A esse respeito, vale a pena retomar as palavras de Cicero (2005, p. 260), quando afirma:

Embora o mythos seja o discurso irreiterável/irreiterativo, é às vezes possível, ao menos em princípio, separá-lo do fluxo mítico e considerá-lo como se fosse epos. Posso, por exemplo, repetir uma sentença que escute de outra pessoa, ou que eu mesmo diga. Posso fazê-lo por admiração ou por sarcasmo, ou para memorizá-la. Ao separá-la do fluxo mítico, e considerá-la independentemente do ato de fala que ela tinha a função de cumprir, estarei tomando-a como um objeto de contemplação ou de análise. Para tanto, porém, terei de reiterá-la, e, na medida em que fizer isso, efetivamente a terei transformado em epos. Não será, é claro, um epos stricto sensu, pois não terá ainda se tornado social ou institucionalmente reiterável; mas será uma espécie de proto-epos. De qualquer maneira, um mythos assim considerado estará tendo uma função épica. 
Como deixa entrever a citação acima, as duas premissas por mim assinaladas partem de objetos diferentes, mas convergem para uma mesma direção. Ou seja, tanto faz "dizer uma mesma coisa com palavras diferentes" como "dizer coisas diferentes com uma mesma palavra": o produto final nunca será um epos ou um mythos puro. Mas é sobre a segunda premissa que gostaria de me debruçar, pois ela dá os indícios para compreender as causas e os modos de um texto tornar-se reiterativo ou reiterável numa prática discursiva.

Assim, ao afirmar que "podemos dizer a mesma coisa com palavras diferentes", devo ter em mãos dois textos (objetos) diferentes, cujo conteúdo é semelhante, mas cujas palavras e/ou sua disposição sejam diferentes. Creio que esta discussão já foi parcialmente feita quando apontados os quatro significados e os cinco elementos significantes amovíveis ${ }^{3}$, ou seja, o mythos e o epos das narrativas de enterro pantaneira, com base no conjunto decorrente da pesquisa de campo. No entanto, deve-se lembrar de que tal premissa foi explorada no que toca à (re)significação de textos oriundos de um mesmo arquétipo, ou seja, de um texto em estado latente derivado de um conjunto de temas mais ou menos comuns. Para levar a reflexão adiante, é necessário que se pense na reiteração de idéias presentes nos textos e não de textos com partes reiteráveis.

Quando atualizado, um texto pode conter pensamentos que são recorrentes em outros, mesmo sendo ambos oriundos de arquétipos distintos. Assim, a narrativa de enterro com significado logro pode apresentar uma infinidade de discursos como: "os amigos nem sempre são confiáveis", "não confie em estranhos", "os ricos sempre enganam os pobres" etc. Estes discursos podem ser reiteráveis em outros textos com arquétipos que não tenham nada a ver com o enterro. Nesse caso, a premissa "podemos dizer a mesma coisa com palavras diferentes" continua válida, só que a reiteratividade ocorre apenas no campo do conteúdo e não do campo do significante.

No exemplo dado acima por Antonio Cicero, uma sentença repetida inúmeras vezes não se torna um epos stricto sensu, pois as situações em que ela é repetida (ironia, sacarmos, memorização etc.) variam e, conseqüentemente, seus atos de fala. O que quero demonstrar, porém, é o outro lado de uma mesma moeda: uma idéia ou conteúdo é reiterativo, valendo-se de enunciados diferentes. Não desejo, com isso, afirmar que o ato de fala per se é reiterativo, pois a relação entre os ouvintes e o enunciador e a situação de enunciação que cerca o que é enunciado nunca se repetem. Mesmo uma peça de teatro com o mesmo cenário, figurino e falas decoradas, mesmo que tais falas, modos de entonação e tempo de enunciação possam ser repetidos, o que é bastante implausível, ela terá sempre um público renovado, cuja recepção se dá de modo específico. Logo, o que pode ser reiterado num ato de fala é o discurso.

\section{O caso do cururu e da narrativa de enterro}

Para levar adiante essa reflexão sobre a reiteratividade na narrativa oral pantaneira, elegi dois textos muito diferentes quanto ao gênero, mas cujo discurso foi reiterado, pelo menos, em dois diferentes contextos de enunciação (ou atos de fala), convergindo para um mythos que se torna reiterável não pela repetição do epos, mas, ao contrário, pela permanência da idéia.

O primeiro texto é uma quadra de um cururu pantaneiro, composta pelo grupo "Violeiros do Senhor", de Corumbá, MS, e entoada por seu Agripino Magalhães, líder do grupo. O segundo texto é uma atualização das narrativas de enterro feita por seu Inacinho, membro do grupo de cururu Violeiros do Senhor, com o significado de um logro. Passo, agora, para a apresentação de dois textos coletados na cultura oral pantaneira:

Texto 1

Marrequinha da lagoa,

Tuiuiú do Pantanal

Marrequinha pega peixe

Tuiuiú já vem tomá (Trovo de Cururu - Grupo Violeiros do Senhor - Corumbá, MS)

\section{Texto 2}

Entrevistador: Seu Inácio, o senhor sabe história de enterro?

Já, já me contaram. Tem aqui memo, tem uma... Morei em cima dum aqui neste Ladário. Teve uma casa ali perto dum frigorífico, uma casa grande de pedra. Eu aluguei. Ali eu tinha minha lancha.

\footnotetext{
${ }^{3}$ Tomo as partes aqui como um epos híbrido e não stricto sensu.
} 
É... perto do frigorífico. Tá lá. Desmancharam... agora é campo de colégio. Moremo dois ano ali. Aí que vim mudar aqui. Mudemo de lá, entreguemo a casa. Veio outro de lá e alugou a casa e ficou. Aí saiu.

Entrou outro lá... o dono da casa. Aí, ele chegou lá, quando foi um dia, disse que chegou três rapaz, duas caminhoneta. Aí, falou pra ele, esqueci o nome do cara:

Óia, rapaz, eu vim aqui... nós vamo morar nessa aí, nós compremo essa casa e ocê caça jeito de mudar. Nós vamo morar.

Mas como? Mudemo num tá nem dois mês, nem paguei, num tá certo, tá marcado quanto tempo que eu posso mora aqui, pra mim saí da casa.

Não, ocê vai lá tira tudinho, nóis paga tudo o seu tempo!

Agora esqueci o nome dele é um amigo meu.

Falou:

- O senhor pode mudar daí, que nós paga tudinho, nós vai morar aí. Pode caçar casa, eu pago aqui e pago o tempo que cê vai... pra pagar aí.

Aí catô a casa, arrumô a casa, ele veio pediu tudo o dinheiro prele, pagô tudo que ele tinha devendo, deu pra ele. Ele ficô lá na casa. Ficaram lá na casa. E quando foi um belo dia, diz que os homem sumiu!

Dentro da casa que tava lá aberta, no quarto de eu dormi, que era minha cama, tiraram um tacho dessa grossura assim.

Um tacho! E fizeram... ficou o tacho aí, tudo mundo viu ... Saber pra onde que foi? Ficou o buraco lá, feito desse tamanho. Eu vi. Entrei lá na casa, tava cum a porta aberta, entrei lá. Tava tudo aberto... aí a dona falou assim:

- Meu fio! ocê perdeu uma sorte! Que os homem tiraram um tacho de ouro aí...

Num sabe o que é que tiraram, mas tá lá, vai lá procê vê !

O homem que era ... que tava alugando ... veio o devogado e falou:

- Seu Inácio, senhô num quer compra essa casa?

Mas quanto senhô tá vendendo?

Tô vendendo por cinco mí réis!

Mas ah! esse é de herança, num sai...

Não, mas eu dou tudo cum papé procê.

Falei:

Ah! essa casa num vai dá mais pra mim comprá, o dinheiro que tenho vou pagar a casa amanhã e pra entregar vim embora pra cá faz tempo...

Essa pessoa num sabe pra onde que ele mora, se é pra Campo Grande, se é, era algum neto desse home, veio que quando esse aí... aí desmanchou a casa .... Vem, vendeu, venderam pro colégio que fez campo de casa lá pra trás ... prantá milho, prantá mandioca.

Esse... esse aconteceu aí!

Aparentemente, os textos não apresentam ligação alguma entre si, nem pelo ato de fala em que são atualizados. O primeiro é acompanhado de instrumento e é cantado, o segundo é narrado e encontrase numa situação de entrevista. A quadra foi gravada na casa do líder do grupo em 1995, em Corumbá, com a presença de vários membros. A narrativa oral, na casa de seu Inacinho, em Ladário, durante uma entrevista de história oral de vida em 2000. Não há, à primeira vista, uma reiteratividade entre os dois textos.

Num primeiro tempo, a quadra parece retratar o pitoresco e ser ingênua, centrando-se na representação da natureza pantaneira. Tal impressão começa a se degradar quando os versos são comentados por seu Agripino. Ele se refere a um pedaço de terra às margens do rio Paraguai, ocupada por pequenos produtores, sob aceite dos proprietários, que começaram a fazer seu roçado. $\mathrm{O}$ sucesso nas vendas de frutas e verduras chegou aos ouvidos dos "grandes fazendeiros", que entraram na justiça, reivindicando a posse da terra. Os roceiros perderam suas plantações e tiveram que desocupar a terra. Os versos são uns dos mais conhecidos do grupo, que faz questão de entoá-los e, em seguida, comentar a metáfora.

Desse modo, o discurso de que "os proprietários tiram proveito daqueles que ocupam a terra para produzir" se faz presente na explicação da criação poética do texto. Em outras palavras: esse discurso é reiterado à medida que a metáfora é descortinada pela voz do próprio intérprete. ${ }^{4}$

Já na narrativa de seu Inacinho, este discurso está mais evidente e, nesse sentido, pode-se falar de uma reiteração discursiva, visto que ele já compartilhava desse pensamento por fazer parte do grupo

\footnotetext{
${ }^{4}$ Há também situações em que apenas o epos permanece reiterável. Uma pesqui sadora, durante o II Literamérica, ocorrido em Cuiabá, no dia 16 de setembro de 2006, alertou-me para o fato de que já ouviu do mesmo grupo os mesmos versos e que a explicação dada era a de que o pássaro maior tuiuiú (macho) se insinua para a marrequinha (fêmea) e, assim, a metáfora diz respeito ao homem que flerta com a mulher numa roda de cururu. Nesse sentido, há uma outra significação para o epos e os cururuzeiros "dizem coisas diferentes com as mesmas palavras". Isso ocorre muito quando se trata de enunciado em verso, pois ele é mais fácil de ser reiterável, uma vez que o ritmo e as palavras são memorizados com mais facilidade.
} 
liderado por seu Agripino. O que é mais interessante na narrativa de enterro de seu Inacinho é como ele se vale de uma dupla reiteração. Ele ocupa-se de duas partes, a marcação, pela qual o narrador define o lugar em que o tesouro está enterrado, e o desenlace, pelo qual o narrador, quando é também o protagonista da história, sempre perde o enterro. E, noutro sentido, ele se vale da reiteração do discurso, presente no seu cotidiano de cururuzeiro, quando utiliza a metáfora da marrequinha (peixe pequeno) e do tuiuiú (peixe grande). Assim como em sua narrativa de enterro, em que seu conhecido foi logrado pelos proprietários da casa, a metáfora da quadra de cururu está reiterando o discurso de que os proprietários tiram vantagem sobre os desapossados, diga-se, os mais pobres. Aí se encontra o mythos com função de epos.

Ainda cabe esclarecer mais uma questão: estou falando em mythos e discurso como se fossem sinônimos e, apesar de um poder ser tomado ad hoc com a função do outro, pois o conteúdo contém o discurso, este último apresenta uma finalidade de inserção do sujeito como voz social. Dessa maneira, deve-se levar em conta o fato de que a enunciação do narrador/cantador é uma maneira de ele se definir enquanto um sujeito social, sendo que seu enunciado, numa cultura oral, ultrapassa as fronteiras do individual, acercando-se de valores e etiquetas coletivas. A idéia de que o peixe grande rouba o peixe pequeno não figura apenas como um conteúdo de um pequeno acontecimento entre os pássaros, mas de uma intenção de o cantador denunciar uma situação social e criar uma identidade para si em consonância com seu grupo.

O discurso cria-se a partir de uma intencionalidade e é manifestado com o desejo de que as palavras operem transformações concretas no mundo - desejo nem sempre realizável, é verdade. Assim, o discurso encontra-se no tempo, é reiterativo. Apesar disso, sua importância reside no contexto em que foi enunciado e não em sua trajetória histórica. Por isso Foucault (2000, p. 28) afirma que "Não é preciso remeter o discurso à longínqua presença da origem; é preciso tratá-lo no jogo de sua instância". Desdobrando tal afirmação, é possível dizer que o discurso pode ser analisado à luz do ato de fala que o anima.

Portanto, se ele se encontra como um elemento reiterativo no mythos com função de epos, significa dizer que o discurso assume, durante o ato de fala, a função de marcar a identidade de um sujeito no mundo. Mas o que os atos de fala acima citados têm em comum, já que são tão diferentes conforme havia assinalado? A resposta é que ambos transcorrem em meio a uma cultura oral. Assim, a reiteração do discurso e da narrativa acaba tendo uma função social de fixar conhecimentos, valores e tradições numa comunidade cujo meio de comunicação não prescinde da memória oral. Acredito que esta é a principal resposta à questão que levantei logo no início deste artigo, a respeito das causas que levam uma narrativa a se repetir.

\section{BIBLIOGRAFIA E FONTES ORAIS}

BARTHES, Roland. Introdução à análise estrutural da narrativa. In: BARTHES, Roland et al. Análise estrutural da narrativa. 4.ed. Petrópolis: Vozes, 1976. p. 19-60.

CICERO, Antonio. Finalidades sem fim. São Paulo: Cia. das Letras, 2005.

CURURU, siriri \& cia (filme-vídeo). Produção: Frederico A. G. Fernandes; Eudes F. Leite. Corumbá: Ceuc/UFMS, 1995. 130min (aprox.)., color., son., VHSc.

ENTREVISTA Inácio de Souza Brandão (filme-vídeo). Produção: Eudes F. Leite; Frederico A. G. Fernandes. Corumbá: Ceuc/UFMS, 2000. 120min (aprox.), color., son., VHSc.

FERNANDES, F. A. Garcia. A voz em performance: uma abordagem de narrativas e versos da cultura oral pantaneira. 342 p. Tese (Doutorado em Letras). Faculdade de Ciências e Letras de Assis Universidade Estadual Paulista, 2003.

FOUCAULT, M. A arqueologia do saber. 6.ed. Trad. Luiz F. Baeta Neves. Rio de Janeiro: Forense Universitária, 2000.

LORD, A. B. The singer of tales. Cambridge/London: Harvard University Press, 1960.

PROPP. V. I. Morfologia do conto maravilhoso. Trad. Jasna Paravich Sarhan. Rio de Janeiro: Forense, 1984.

ZUMTHOR, P. A letra e a voz: a literatura medieval. Trad. Jerusa Pires Ferreira e Amálio Pinheiro. São Paulo: Cia. das Letras, 1993.

ZUMTHOR, P. Escritura e nomadismo. Trad. Jerusa Pires Ferreira. São Paulo: Ateliê, 2005. 